\title{
Solubility Determination and Correlation Analysis of 5-Chloropyrazin-2-Amine in Several Mixed Solvents
}

\author{
Guangyu Xu, Fanyuan Zhang, Zhenghui Li*
}

School of Materials and Chemical Engineering, Ningbo University of Technology, Ningbo, Zhejiang 315211,

People's Republic of China

Corresponding author. Phone: + 86574 87616023; Fax: + 8657487615880 .

E-mail address: zhenghui.li@nbut.edu.cn 


\section{Section (a): Correlation Models}

Jouyban-Acree Model. The model is expressed as eq (1) ${ }^{1-5}$

$\ln x_{\mathrm{w}, \mathrm{T}}=w_{1} \ln x_{1, \mathrm{~T}}+w_{2} \ln x_{2, \mathrm{~T}}+\frac{w_{1} w_{2}}{T / \mathrm{K}} \sum_{\mathrm{i}=0}^{2} J_{\mathrm{i}}\left(w_{1}-w_{2}\right)^{\mathrm{i}}$

where $x_{\mathrm{w}, \mathrm{T}}$ denotes the mole fraction solubility of solute in solvent mixtures at temperature $T / \mathrm{K} ; w_{1}$ and $w_{2}$ are the mass fraction of solvents 1 and 2 in the absence of the solute, respectively; $x_{1, \mathrm{~T}}$ and $x_{2, \mathrm{~T}}$ are the solute solubility in mole fraction in neat solvent; and $J_{\mathrm{i}}$ are the Jouyban-Acree model parameters.

Van't Hoff-Jouyban-Acree Model. The Van't Hoff equation is expressed as eq (2).

$\ln x_{\mathrm{T}}=A+\frac{B}{T / \mathrm{K}}$

Substituting Van't Hoff equation into eq (1) for pure solvents, the model expressed as eq (3). ${ }^{6-9}$

$\ln x_{\mathrm{w}, \mathrm{T}}=w_{1}\left(A_{1}+\frac{B_{1}}{T / \mathrm{K}}\right)+w_{2}\left(A_{2}+\frac{B_{2}}{T / \mathrm{K}}\right)+\frac{w_{1} w_{2}}{T / \mathrm{K}} \sum_{i=0}^{2} J_{i}\left(w_{1}-w_{2}\right)^{i}$

$A_{1}, B_{1}, A_{2}, B_{2}$ and $J_{\mathrm{i}}$ are equation parameters.

Modified Apelblat-Jouyban-Acree Model. The expression of the modified Apelblat equation is described as ${ }^{10,11}$

$\ln x_{\mathrm{T}}=A+\frac{B}{T / K}+C \ln (T / K)$

Where $A, B$, and $C$ are equation parameters; and $x_{\mathrm{T}}$ is the mole fraction solubility in selected co-solvent mixtures at absolute temperature $T$ in Kelvin.

The modified Apelblat-Jouyban-Acree model is obtained by substituting eq (4) into eq (1) as followed ${ }^{6,8}$ 
$\ln x_{\mathrm{w}, \mathrm{T}}=w_{1}\left[A_{1}+\frac{B_{1}}{T / \mathrm{K}}+C_{1} \ln (T / K)\right]+w_{2}\left[\left(A_{2}+\frac{B_{2}}{T / \mathrm{K}}+C_{2} \ln (T / K)\right]+\frac{w_{1} w_{2}}{T / \mathrm{K}} \sum_{i=0}^{2} J_{\mathrm{i}}\left(w_{1}-w_{2}\right)^{\mathrm{i}}\right.$

The experimental solubility in four co-solvent mixtures are correlated and calculated with eqs (1),

(3) and (5) by using the method of non-linear regression, and the objective function is defined as

$$
F=\sum_{\mathrm{i}=1}\left(\ln x_{\mathrm{i}}^{\mathrm{e}}-\ln x_{\mathrm{i}}^{\mathrm{c}}\right)^{2}
$$

Furthermore, the relative average deviation $(R A D)$ and root-mean-square deviation $(R M S D)$ to evaluate three cosolvency models are employed and described as eqs (7) and (8).

$$
\begin{aligned}
& R A D=\frac{1}{N} \sum\left(\frac{\left|x_{\mathrm{w}, \mathrm{T}}^{\mathrm{c}}-x_{\mathrm{w}, \mathrm{T}}^{\mathrm{e}}\right|}{x_{\mathrm{w}, \mathrm{T}}^{\mathrm{e}}}\right) \\
& R M S D=\sqrt{\frac{\sum_{i=1}^{N}\left(x_{\mathrm{w}, \mathrm{T}}^{\mathrm{c}}-x_{\mathrm{w}, \mathrm{T}}^{\mathrm{e}}\right)^{2}}{N}}
\end{aligned}
$$

where $N$ is the number of experimental data points. $x_{\mathrm{w}, \mathrm{T}}^{\mathrm{e}}$ signifies the mole fraction solubility determined in this study; and $x_{\mathrm{w}, \mathrm{T}}^{\mathrm{c}}$, the mole fraction solubility calculated with the corresponding cosolvency model. 


\section{REGERENCES}

(1) Jouyban, A. In Silico Prediction of Drug Solubility in Water-Dioxane Mixtures Using the Jouyban-Acree Model. Pharmazie. 2007, 62, 46-50.

(2) Li, R. R.; Tang, T.; Yin, X. F; Yao, L. S.; Lin, Z. P.; Zhang, L.; Gao, X.; Xu, X. J.; Zhao, J.; Han, D. M. Solubility of Naftopidil in Pure and Mixed Solvents at 273.15 to $313.15 \mathrm{~K}$ and Its Correlation with the Jouyban-Acree and CNIBS/R-K Models. J. Chem. Thermodyn. 2020, 145, 105-109.

(3) Li, W. X.; Farajtabar, A.; Wang, N.; Liu, Z. T.; Fei, Z. H.; Zhao, H. K. Solubility of Chloroxine in Aqueous Co-Solvent Mixtures of $N, N$-Dimethylformamide, Dimethyl Sulfoxide, $N$-Methyl-2-Pyrrolidone and 1,4-Dioxane: Determination, Solvent Effect and Preferential Solvation Analysis. J. Chem. Thermodyn. 2019, 138, 288-296.

(4) Jouyban, A. Acree, W. E. Mathematical Derivation of the Jouyban-Acree Model to Represent Solute Solubility Data in Mixed Solvents at Various Temperatures. J. Mol. Liq. 2018, 256, 541547.

(5) Li, Y. X.; Mou, Y.; Zhu, Y.; Liu, J. H.; Liu, J.; Zhao, H. K. Equilibrium Solubility Determination and Thermodynamic Aspects of Aprepitant (Form I) in Four Binary Aqueous Mixtures of Methanol, Ethanol, Acetone And 1,4-Dioxane. J. Chem. Thermodyn. 2020, 149, 106-117.

(6) Jouyban, A.; Fakhree, M. A. A.; Acree, W. E. Jr. Comment on "Measurement and Correlation of Solubilities of (Z)-2-(2-Aminothiazol-4-Yl)-2-Methoxyiminoacetic Acid in Different Pure Solvents and Binary Mixtures of Water + (Ethanol, Methanol, or Glycol). J. Chem. Eng. Data. 2012, 57, $1344-1346$.

(7) Jouyban, K.; Agha, E.; Hemmati, S.; Martinez, F.; Jouyban, A. Solubility of 5-Aminosalicylic Acid in N-Methyl-2-Pyrrolidone + Water Mixtures at Various Temperatures. J. Mol. Liq. 2020, 310, 113-123. 
(8) Yang, G.; Zhang, J. Q.; Huang, C. J.; Song, X.; Xu, R. J. Equilibrium Solubility Investigation and Thermodynamic Computational Modeling of Halosulfuron-methyl in a Series of Cosolvent Mixtures at Temperature Range of (278.15-323.15) K. J. Chem. Eng. Data. 2021, 66, 271-279.

(9) Ahad, A.; Shakeel, F.; Alfaifi, O. A.; Raish, M.; Ahmad, A.; Al-Jenoobi, F. I.; Al-Mohizea, A. M. Solubility Determination of Raloxifene Hydrochloride in Ten Pure Solvents at Various Temperatures: Thermodynamics-Based Analysis and Solute-Solvent Interactions. Int. J. Pharm. 2018, 544, 165-171.

(10) Apelblat, A.; Manzurola, E. Solubilities of o-Acetylsalicylic, 4-Aminosalicylic, 3,5-Dinitrosalicylic, and $\beta$-Toluic Acid, and Magnesium-Dl-Aspartate in Water from $T=(278$ to 348) K. J. Chem. Thermodyn. 1999, 31, 85-91.

(11) Apelblat, A.; Manzurola, E. Solubilities of L-Glutamic Acid, 3-Nitrobenzoic Acid, $\beta$-Toluic Acid, Calcium-L-Lactate, Calcium Gluconate, Magnesium-DL-Aspartate, and Magnesium-L-Lactate in Water. J. Chem. Thermodyn. 2002, 34, 1127-1136. 
Section (b):

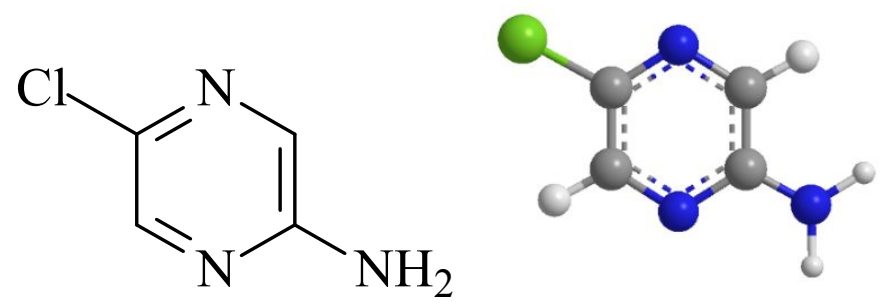

Fig S1. Chemical structure of 5-chloropyrazin-2-amine. 


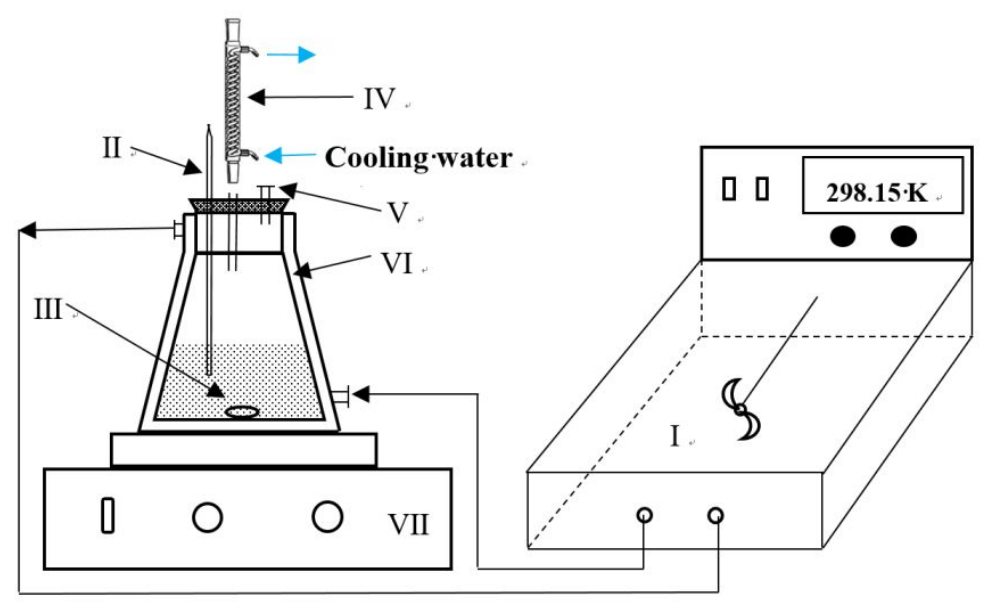

Fig. S2. Schematic diagram of solubility measuring device: I, smart thermostatic water bath; II, mercury-in-glass thermometer; III, magnetic stirrer; IV, condenser; V, sampling port; VI, sandwich flat bottom flask; VII, stirrer controller. 


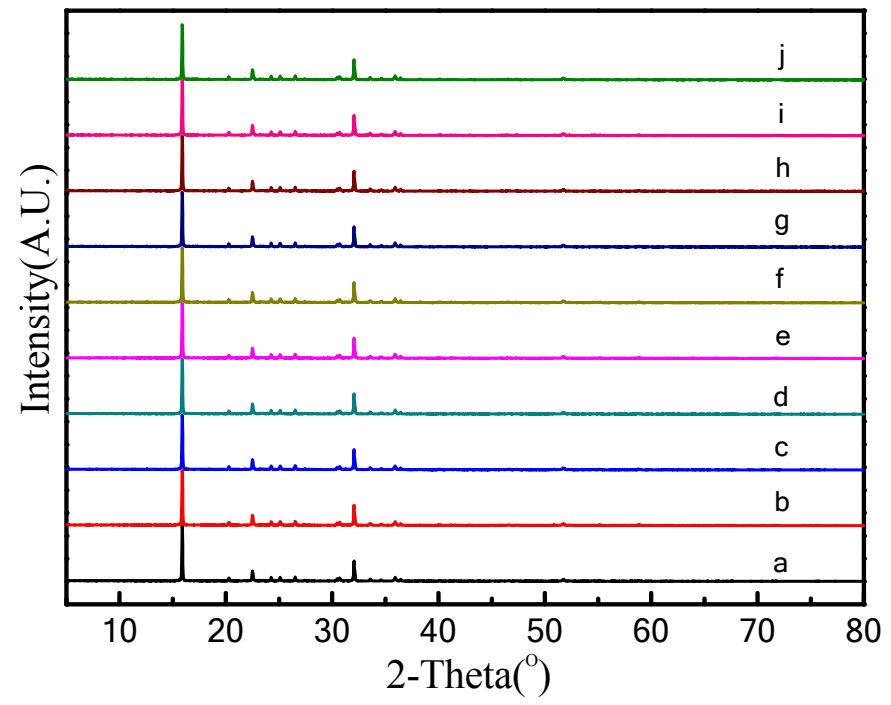

Fig. S3. XPRD spectrogram patterns of 5-chloropyrazin-2-amine in pure solvents and different cosolvency systems compared with the raw material. (a) raw material; (b) crystallized in methanol; (c) crystallized in n-propanol; (d) crystallized in EG; (e) crystallized in ethanol; (f) crystallized in water; (g) crystallized in methanol + water mixture; (h) crystallized in $n$-propanol + water mixture; (i) crystallized in EG + water mixture; (j) crystallized in ethanol + water mixture. 

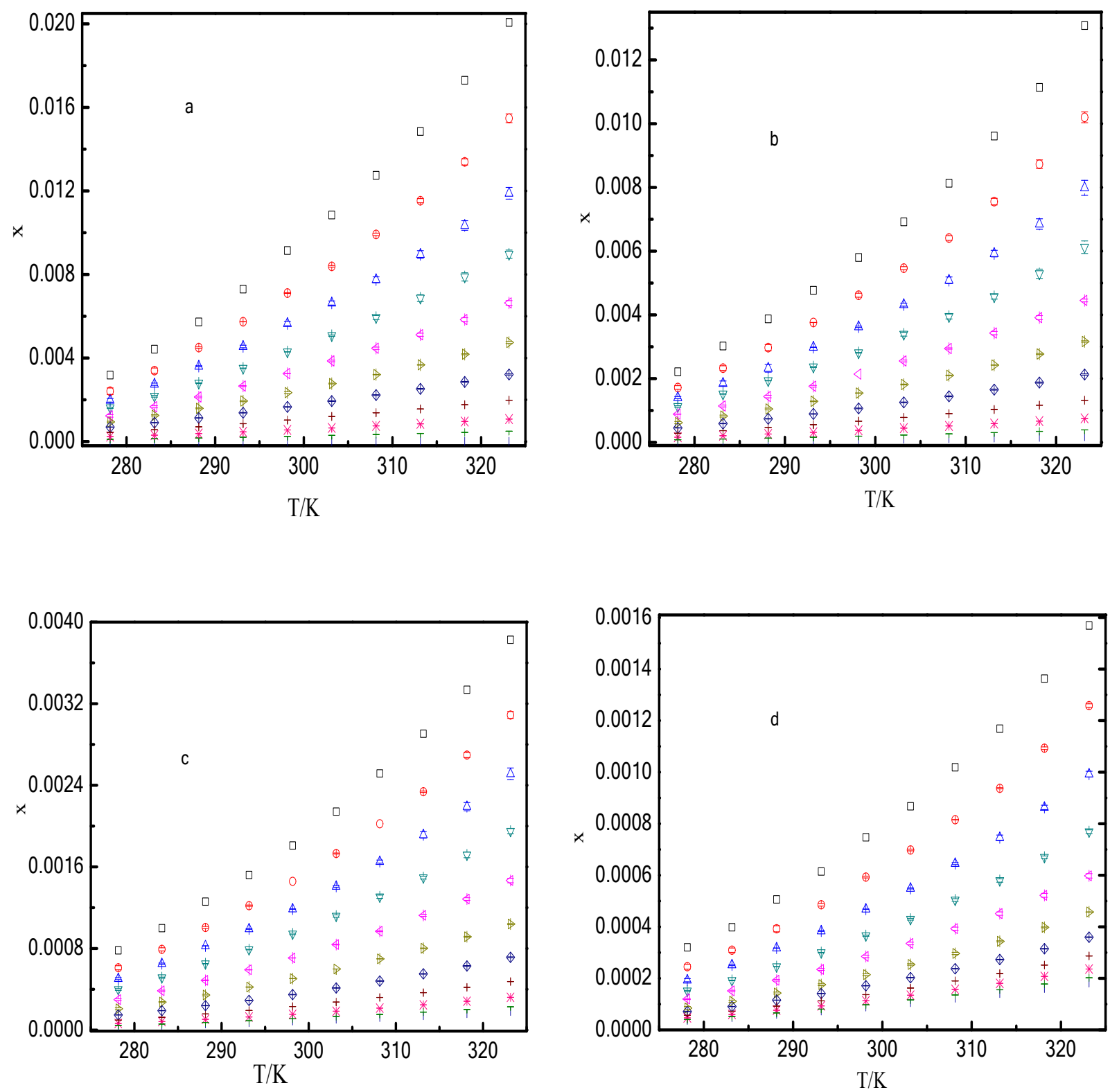

Fig S4. Deviation between Jouyban-Acree model calculation results and 5-chloropyrazin-2-amine experiment solubility in (a), methanol + water; (b), ethanol + water; (c), $n$-propanol + water; (d), EG+ water. w is the mass ratio of organic solvent: $\square, \mathrm{w}=1 ; \bigcirc, \mathrm{w}=0.9 ; \triangle, \mathrm{w}=0.8 ; \nabla, \mathrm{w}=0.7 ; \triangleleft, \mathrm{w}=0.6 ; \triangleright, \mathrm{w}=0.5 ; \diamond, \mathrm{w}=0.4 ; \square+, \mathrm{w}=0.3$; $\times, \mathrm{w}=0.2 ;-, \mathrm{w}=0.1 ; \mid, \mathrm{w}=0$. 

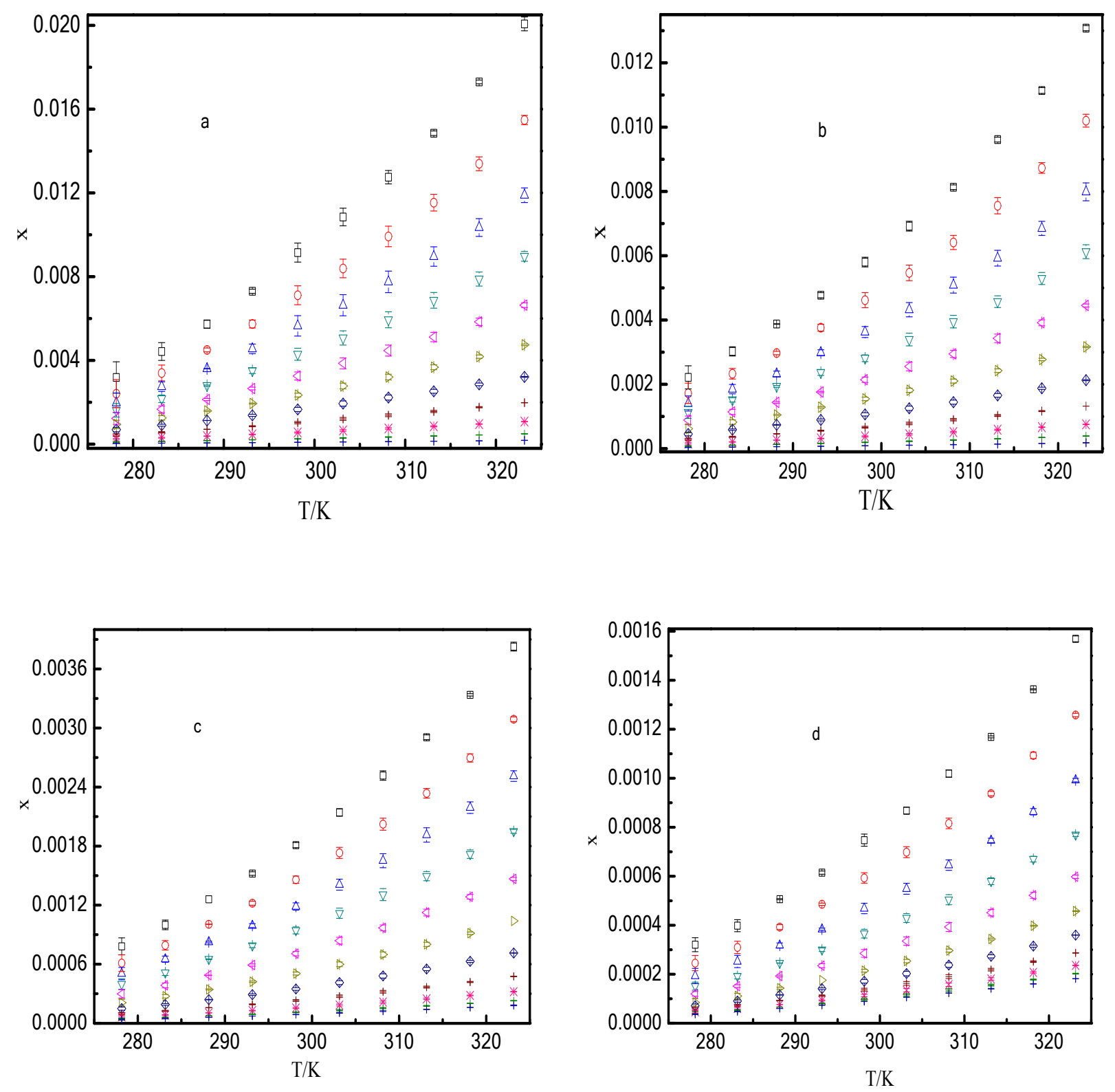

Fig S5. Deviation between Van't Hoff-Jouyban-Acree model calculation results and 5-chloropyrazin-2-amine experiment solubility in (a), methanol + water; (b), ethanol + water; (c), $n$-propanol + water; (d), EG + water. w is the mass ratio of organic solvent: $\square, \mathrm{w}=1 ; \bigcirc, \mathrm{w}=0.9 ; \triangle, \mathrm{w}=0.8 ; \nabla, \mathrm{w}=0.7 ; \triangleleft, \mathrm{w}=0.6 ; \triangleright, \mathrm{w}=0.5 ; \diamond, \mathrm{w}=0.4 ; \square$ ,$+ \mathrm{w}=0.3 ; \times, \mathrm{w}=0.2 ;-, \mathrm{w}=0.1 ; \mid, \mathrm{w}=0$. 

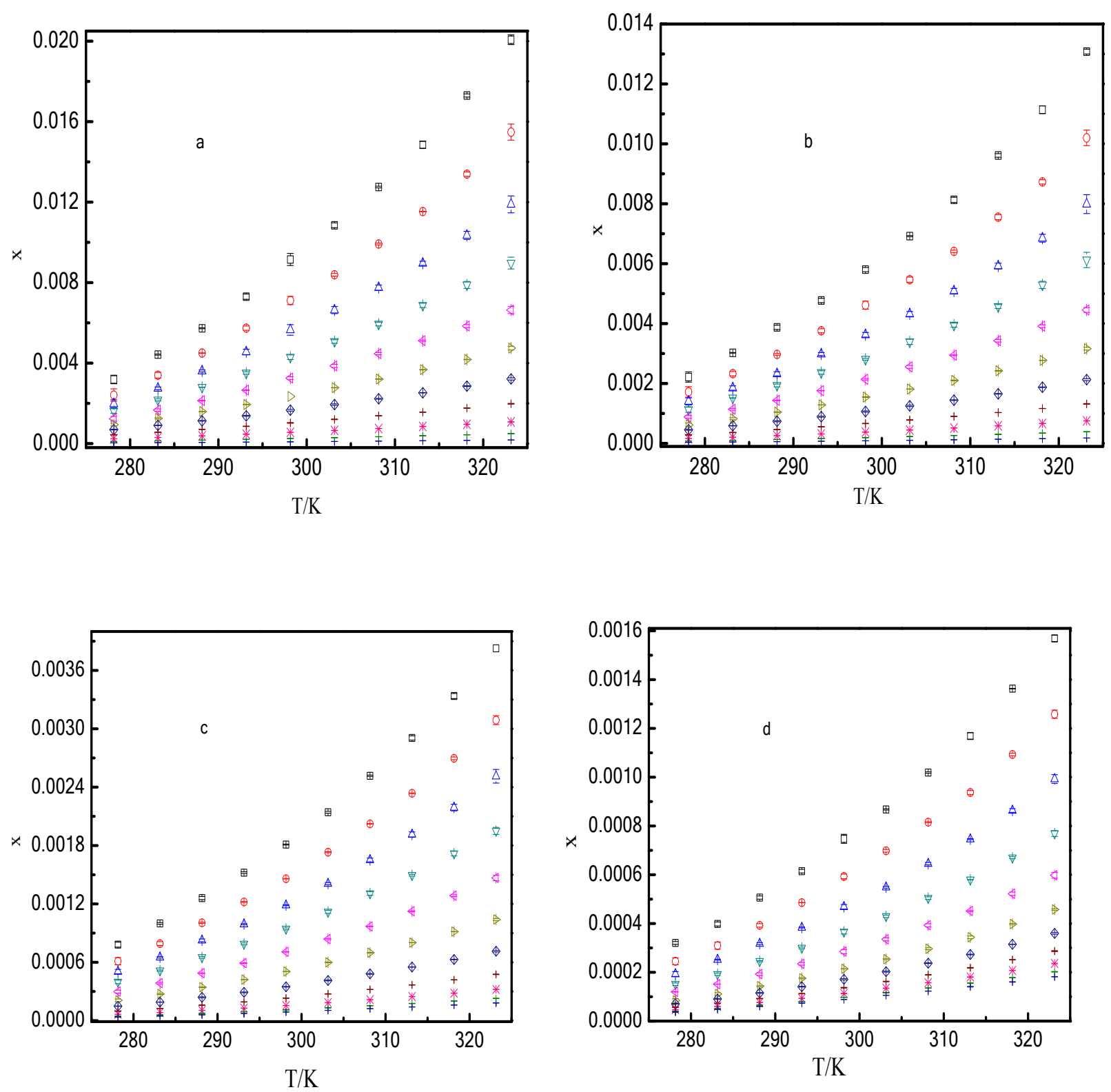

Fig S6. Deviation between Modified Apelblat-Jouyban-Acree model calculation results and 5-chloropyrazin-2-amine experiment solubility in (a), methanol + water; (b), ethanol + water; (c), $n$-propanol + water; (d), EG + water. $\mathrm{w}$ is the mass ratio of organic solvent: $\square, \mathrm{w}=1 ; \bigcirc, \mathrm{w}=0.9 ; \triangle, \mathrm{w}=0.8 ; \nabla, \mathrm{w}=0.7 ; \triangleleft$, $\mathrm{w}=0.6 ; \triangleright, \mathrm{w}=0.5 ; \diamond, \mathrm{w}=0.4 ; \square+, \mathrm{w}=0.3 ; \times, \mathrm{w}=0.2 ;-, \mathrm{w}=0.1 ; \mid, \mathrm{w}=0$. 